Williams, J. G. K., A. R. Kubelki, K. J. LivaK and S. V. TINGEY (1990): DNA polymorphisms amplified by arbitrary primers are useful as genetic markers. Nucleic Acids Res. 18: 6531-6535.

Wright, A. J. and R. P. Mowers (1994): Multiple regression for molecular-marker, quantitative trait data from large F2 a populations. Theoretical and Applied Genetics 89: 305-312.

WrIGHT, S. (1978): Evolution and the genetics of Populations ( $3^{\text {rd }}$ edition). University of Chicago Press, Chicago.

XIA, D. A., Z. G. WeI, C. P. YANG and G. J. LIU (2008): Analysis of ISSR and SCAR Markers associated with birch fiber length trait. Journal of Northeast Forestry University 39: 1-4.

Yan, G., J. Romero-Severson, M. Walton, D. D. Chadee and D. W. Severson (1999): Population genetics of the yellow fever mosquito in Trinidad: comparisons of amplified fragment length polymorphism (AFLP) and restriction fragment length polymorphism (RFLP) markers. Mol. Ecol. 8: 951-963.
YeH, F. C. and Y. A. EL-KASsAbY (1980): Enzyme variation in natural populations of Sitka spruce (Picea sitchensis). Genetic variation patterns among trees from 10 provenances. Canadian Journal of Forest Research 10: 415-422.

Yonash, N., E. D. Heller, J. Hillel and A. CAHANER (2000): Detection of RFLP markers associated with antibody response in meat-type chickens: haplotype/genotype, single-band and multiband analyses of RFLP in the major histocom-patibility complex. Journal of Heredity 91: 24-30.

Zhao, Y., H. WANG, W. Chen and Y. Li (2014): Genetic Structure, Linkage Disequilibrium and Association Mapping of Verticillium Wilt Resistance in Elite Cotton (Gossypium hirsutum L.) Germplasm Population. PLoS ONE 9(1): e86308. doi:10.1371/journal.pone.0086308

Zhivotovsky, L. A. (1999): Estimating population structure in diploids with multilocus dominant DNA markers. Mol. Ecol. 8: 907-913.

\title{
Inducing genetic variation in growth related characteristics of poplar germplasm, by producing inter-specific hybrids between $P$. alba and $P$. euphratica
}

\author{
By H. Mirzaie-Nodoushan ${ }^{*}$, A. Ghamari-Zare ${ }^{1)}$, F. TAvousi RaD ${ }^{2)}$ and M. Yousefifard ${ }^{3)}$
}

(Received $2^{\text {nd }}$ November 2015)

\begin{abstract}
Crosses were made between two Populus species to create two hybrid groups, $P$. alba $+*$ $P$. euphratica $\widehat{\sigma}$ and $P$. euphratica $+* P$. alba $\hat{\sigma}$. Aseptic immature hybrid seeds were first grown on MS medium. Hybrid seedlings were then acclimatized and grown in greenhouse conditions and transplanted to an experimental field. Growth related characteristics were recorded on 307 three years-old seedlings of new inter-spe-

\footnotetext{
1) Associ. Prof., Forests and Rangelands Research Institute, Agricultural Research, Education and Extension Organization (AREEO), Tehran, I.R. Iran.

2) M.Sc. Payam-Noor University, Isfahan, I.R. Iran.

$\left.{ }^{3}\right)$ Assist. Prof., Payam-Noor University, Tehran, I.R. Iran.

*) Corresponding author: Prof. H. MiRzaie-Nodoushan. Forests and Rangelands Research Institute, Agricultural Research, Education and Extension Organization (AREEO), Tehran, I.R. Iran. Phone: 0098-91-26662603, Fax: 0098-21-44580288.

E-Mail: nodoushan2003@yahoo.com
}

cific hybrids of six half-sib families, in order to assess possible potentials of the two hybrid groups. Double nested analysis of variance revealed significant differences between the hybrid groups and siblings based on majority of the studied characters. The hybrid groups formed two distinct groups for some of the studied characteristics which implied maternal effects of inheritance on the traits. The first hybrid group had more but shorter and closer branches than the second group. Adaxial stomata number for the two hybrid groups varied between 4.7 to 123 . Whereas, there were no such strong differences between vegetative characteristics of the two groups. The second hybrid group had a very condense layer of white fuzz on its abaxial leaf surface, inherited from its female parents. This may lead to suggest some kinds of photosynthesis and respiration functions such as leaf sub-stomatal chambers' functions for the mentioned fuzzy trichomes of 
the second hybrid group and their female parental species, $P$. alba. In essence, 307 new divergent poplar hybrid genotypes were produced by which ecological zone of poplar species could be extended in the country as well as high yielding genotypes would be promising.

Key words: Populus euphratica, Populus alba, Nested ANOVA, Inter-specific hybrids, Adaxial stomata, Morphologic traits.

\section{Introduction}

Inter-specific hybridization may be evolutionary dead end due to infertility or may present hybrid vigor and even exhibit adaptive advantages over the parental species (ARNOLD and MARTIN, 2010). However, inter-specific hybridization is regarded as an important source of new genetic variation (BUTLIN and RITCHIE, 2013) for the situations in which available genetic resources may not be adaptive enough. In some points of views inter-specific hybridization is regarded as an important phenomenon with integral role in evolutionary diversification, adaptation, and biodiversity (TUllus et al., 2009; АввотT et al., 2013) with highly variable outcomes. Although inter-specific hybridization may naturally take place between poplar species, but it is not wise to relay on chance and the mother nature's decision. On the other hand natural inter-specific hybridization does not occur frequently between poplar species in arid and semi-arid areas. Particularly even the most vigorous seeds and seedlings are almost impossible to germinate and grow to adult trees in dry conditions. Meanwhile, harsh climatic conditions in some parts of Iran need superior poplar hybrids with specific characteristics such as drought resistance, desirable commercial important traits, as well as being fast growing to be used commercially by local residents. The mentioned purposes wouldn't be possible to be met through traditional genetic improvement programs on existing germplasm. Present research was performed to achieve new genetic resources to be used in the mentioned areas. Two deciduous popular poplar species in the area are Populus euphratica Oliv. and Populus alba L. with different characteristics. Populus euphratica grows in a wide range of sub-tropics. It shows varying degrees of tolerance, to salinity, water logging, cold and arid conditions. Wide ecological amplitude is the most interesting characteristic of the species. It also has amphistomatous leaves (stomata present on upper and lower leaf surfaces). A misfortune with $P$. euphratica is small and crooked trunks which have made the species commercially useless. In contrast, Populus alba is a timber species with three-lobed fuzzy white leaves, which is mainly growing in temperate areas of Northern hemisphere. It grows mostly upright, which has made it commercially very desirable. Although it is sometimes used as a windbreak tree but it is to some extent susceptible to breakage, for which it can't be grown in open spaces such as parks. Inter-specific hybridization between the two tree species may lead to obtain superior hybrid genotypes with aggregated suitable characters of the two species as well as gaining more wood productivity due to heterosis phenomenon to be used in harsh conditions of central parts of the country, for both commercial and environmental purposes.

The two species seldom mate with one another in the nature, which is because of several reasons. First, the two species have different habitats, as well as highly embryo abortion possibility of the hybrid embryo or immature seeds. Although gametes of the two species are compatible (JAFARI-MOFIDABADI et al., 1998) and easy to cross artificially and propagate vegetatively. During last decades much efforts have been done all over the world to produce poplar inter-specific hybrids (JAFARI-MOFIDABADI et al., 1998; CHAUHAN et al., 2004; MARRON et al., 2007; TulLus et al., 2012) mainly to increase productivity. Biomass productivity in poplars is related to leaf characteristics such as leaf length, leaf width and leaf total area. Genetic diversity either natural diversity or artificially induced diversity along with knowledge of relationship between leaf characteristics and wood productivity would assist scientific efforts to produce desirable genotypes with suitable productivity (LOPEZ et al., 2004). In present study series of crosses were performed between the two poplar species during 2013, in order to produce new genotypes of poplar hybrids to find some multi purposes superior genotypes, by studying their morphological and micro-morphological characteristics.

\section{Materials and Methods}

The study was started early 2013, at headquarter of Research Institute of Forests and Rangelands, located in West of Tehran, Iran. To 
Table 1. - Parental clones and two groups of inter-specific crosses between two poplar species, $P$. euphratica and $P$. alba.

\begin{tabular}{|c|c|c|c|c|}
\hline Female parenl & Male parent. & Inler-specilic hybrid & Code & No. ol progenies \\
\hline \multicolumn{5}{|c|}{ 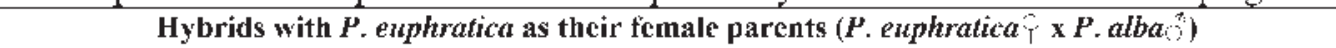 } \\
\hline PeAhvaz & $\mathrm{Pa} 72 / 2 \mathrm{I}$ & PeAhva 2 x Pa7221 & PePal & 27 \\
\hline PeAhvaz. & $\mathrm{Pa} 4565$ & PeAhvaz + Pa4565j & $\mathrm{PcPa} 2$ & 30 \\
\hline \multicolumn{5}{|c|}{ Hybrids with $P$ alba as their temale parents $\left(P_{2}\right.$ alba $\left.P_{\text {enphratica }}\right)$} \\
\hline $\mathrm{Pa} 2045$ & PcZaboll & Pa2045 x PeZabol 13 & $\mathrm{PaPc}]$ & 8 \\
\hline $\operatorname{Pa} 5857$ & PeGarden & Pa58570 x PeCrarden & $\mathrm{PaPc}_{2}$ & 71 \\
\hline Pa5857 & Pelabol3 & Pa5857 + PaZabol3 & PaPe3 & 84 \\
\hline $\mathrm{Pa} 2045$ & PeGarden & Pa2045- x PeGardend & PaPe4 & 87 \\
\hline
\end{tabular}

get a wide range of induced genetic variation within produced poplar hybrid genotypes, several male and female trees were selected from P. alba and P. euphratica at a poplar collection which was collected from various parts of the country. The poplar collection was established years before in Karaj research station, a city located in West side of Tehran. Female flowers of selected female parents were covered before anthesis stage with transparent bags to prevent contamination by alien pollens. Branches of the selected male parents, bearing male flowers were collected 4 weeks prior to anthesis and kept in different water-filled containers in several separate laboratories to avoid unwanted pollen contamination. The male flowers brought to anthesis on laboratory benches around two weeks later. Pollens were collected from ripened catkins and stored at $4{ }^{\circ} \mathrm{C}$ until they were used for crossing when female flowers were receptive. Hand pollinations were performed by dusting the collected pollen grains on the targeted female parents' inflorescences, during early morning and repeated for three successive days. Crosses were classified into two groups (Table 1). In the first group of the crosses, female trees of $P$. euphratica were used as female parents and male trees of $P$. alba were used as male parents ( $P$. euphratica + × $P$. alba $\left.{ }^{\star}\right)$. In second group of the crosses, female trees of $P$ alba species were used as female parents and male parents were male trees from $P$. euphratica species ( $P$. alba ㅇ $\times$ P. euphratica $\left.{ }^{\star}\right)$.

Sixty five-day old pollinated catkins were harvested from female plants. Capsules of hybrid seeds were surface sterilized for 2 minutes by $0.2 \% \mathrm{HgCl}_{2}$ followed by well rinsing in sterile distilled water. Immature hybrid seeds were aseptically extracted and cultured on hormone free MS medium (Murashige and Skooge, 1962) in small jam jars. The containers were then incubated at $23 \pm 1^{\circ} \mathrm{C}$ under $16 \mathrm{~h}$ photoperiod, (5000 lux) under light provided by a mixture of sun light and white fluorescent lamps. Several crosses failed to produce enough plantlets to be kept for further studies. Hybrid seedlings then were transplanted into pots containing sterile light medium of pit/perlit (1:1) and acclimatized in a greenhouse. Unequal number of one-year old hybrid seedlings per family (Table 1) were planted to a research field with semi-arid conditions, on rows with $100 \mathrm{~cm}$ between and within rows intervals. Data were recorded on three-year old seedlings for several vegetative characteristics, as well as stomatal measures on three representative and typical leaves of all single plants (307 siblings), sampled constantly from the south-facing side of the

Table 2. - Morphologic characteristics recorded on two groups of full-sib inter-specific hybrid

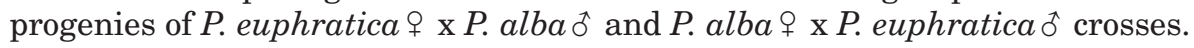

\begin{tabular}{|c|c|c|c|}
\hline Row & Character & Abbrev & Abbreviation \\
\hline 1 & Plant height & $\mathrm{cm}$ & $\mathrm{PH}$ \\
\hline 2 & Collar diameter & min & CD \\
\hline 3 & Btanch number & Total branch mumber & $\mathrm{BN}$ \\
\hline 4 & Jranch length & Average length of the first 5 branches in $\mathrm{cm}$ & I3I. \\
\hline 5 & Branch angle & Average angle with main trunk of the Jirst 5 branches, in Degree & $\mathrm{BA}$ \\
\hline 6 & Leaf length & Average length of 5 representative leaves in $\mathrm{cm}$ & $\mathrm{LL}$ \\
\hline 7 & l.caf width & Average width of 5 representative leaves in cm & I.W \\
\hline 8 & Leaf area & Average area of 5 representalive leaves in $\mathrm{cm}^{2}$ & $\mathrm{LA}$ \\
\hline 9 & Stomata number & Average number of stomata of 9 microseopic scopes counted on 3 leaves & $\mathrm{SN}$ \\
\hline 10 & Stomalaa length & Average length of 5 stomata in micron & $\mathrm{SL}$. \\
\hline 11 & Stomata width & Average width of 5 stomata in micron & $\mathrm{SW}$ \\
\hline
\end{tabular}


young trees based on a randomized complete block design with three replications (Table 2). Leaf blades in the middle of leaves, between the midrib and leaf margin were used to take stomatal print by using colorless nail polish which was removed with clear adhesive tape for stomatal measurements on adaxial surface of the hybrid groups. Stomata were counted and measured on digital images of 9 microscopic scopes (Three scopes per each one of three different leaves, $0.07 \mathrm{~mm}^{2}$ each scope) of the impressions recorded at $400 \mathrm{x}$ magnification of an Olympus 3H2-RFCA microscope. Average numbers of stomata per microscopic scope were converted to number of stomata per $\mathrm{mm}^{2}$.

Since the two groups of crosses were expected to show different behaviors on several characters and the progenies of each cross were different, the data were analyzed based on a nested model (model 1), in which hybrids were nested in groups, and progenies were nested in hybrids. By the mentioned model of analysis of variance main effects of hybrid groups, hybrids nested within the groups, and progenies nested in hybrids on the characteristics were analyzed. All effects of the proposed model were regarded as factors with random effect.

$$
\text { Model 1: } \mathrm{Y}_{\mathrm{ijkl}}=\mu+\eta_{\mathrm{k}}+\alpha_{\mathrm{i}(\mathrm{k})}+\beta_{\mathrm{j}}+\rho_{\mathrm{l}(\mathrm{ik})}+\varepsilon_{\mathrm{ijkl}}
$$

In which

$\mathrm{Y}_{\mathrm{ijkl}}$ is the phenotypic value of the dependent variable observed at $j$ th replication with the $l$ th progeny nested within $i$ th inter-specific hybrid, nested within $k$ th hybrid group. $\mu$ is grand mean common to all observations.

$\eta_{\mathrm{k}}$ is effects of $k$ th hybrid group.

$\alpha_{\mathrm{i}(\mathrm{k})}$ is effects of $i$ th inter-specific hybrid, nested within $k$ th hybrid group.

$\beta_{\mathrm{j}}$ is effects of $j$ th replication.

$\rho_{l(\mathrm{ik})}$ is effects of $l$ th progeny nested within $i$ th inter-specific hybrid, nested within $k$ th hybrid group.

$\varepsilon_{\mathrm{ijkl}}$ is random error associated with the individual plots.

Variance components were estimated using expected mean squares (EMS) of sources of variance in the ANOVA Table. The components with negative value were regarded null then apart from block component of variance, other sources of variance with genetic nature were used to specify percentage of variance components.

Duncan multiple range test was used to classify mean values of the hybrid groups. Pearson correlation coefficients were estimated between all pairs of the recorded variables to describe extent of statistical relationship between the studied variables. Principal components analysis was used to reduce the dimensionality of the data and describe the observed variation in the studied characteristics in another perspective. By summarizing the strongest sources of variation within the first two principal components, they were plotted in a two-dimensional scatter-plot to classify the crosses based on the majority of observed variation in the studied characters.

Table 3. - Mean squares of analysis of variance of six poplar inter-specific hybrid crosses, analyzed based on a double nested model.

\begin{tabular}{|c|c|c|c|c|c|c|c|c|c|c|c|c|}
\hline Sources of variation & D. F, & $\mathrm{PH}^{\mathrm{n+1}}$ & $\mathrm{CD}$ & $13 \mathrm{~N}$ & LSL & BA & LL. & LW & L.A & $\mathrm{SN}$ & $\mathrm{SL}$ & $S W$ \\
\hline Rej]lieation & 2 & $2584^{5 *}$ & $108^{2}$ & $53,0^{\mathrm{TH}}$ & $374^{n 3}$ & $173^{\mathrm{ns}}$ & $17.0^{15}$ & $|7:|^{\cap ะ}$ & $74.1^{\text {h.t. }}$ & $1559^{\circ}$ & $0.9^{n ! 3}$ & $0.5^{\pi b}$ \\
\hline Groups & 1 & $3578^{115}$ & $5.6^{\text {ras }}$ & $303^{\circ "}$ & $23126^{\prime}$ & $6281^{* *}$ & $238^{*}$ & $638^{\circ *}$ & $730.1^{\circ}$ & $477884^{\mathrm{nm}}$ & $2884^{\circ}$ & $1742^{\circ}$ \\
\hline Hybrids trested ir groups & 4 & $1189^{1+s}$ & $164^{*}$ & $14.7^{119}$ & $1984^{118}$ & $145^{\mathrm{ris}}$ & $18.0^{\circ}$ & $1] .0^{n / s}$ & $65.4^{115}$ & $588^{115}$ & $239^{\circ *}$ & $199^{* \prime}$ \\
\hline Progenics nested in hybrids neslud in groups & 99 & $5271^{* *}$ & $62^{44}$ & $33.5^{\pi !}$ & $891^{n:}$ & $95^{*}$ & $5.1^{*}$ & $9.1^{\mathrm{ns}}$ & $32.7^{n *}$ & $372^{\mathrm{n}:}$ & $68^{\mathrm{ns}}$ & $58^{n: 4}$ \\
\hline Епть & 200 & 3335 & 29 & 23,5 & 714 & $7 !$ & 3.8 & 7.4 & 17 & 465 & 69 & 61 \\
\hline
\end{tabular}

${ }^{*}$ and $*$ significantly different at $1 \%$ and $5 \%$ respectively, ns $=$ not significantly different,

***: Abbreviations and scales of the measurements are described in Table 2.

Table 4. - Mean classification of two inter-specific hybrids groups, $P$. euphratica + x $P$. alba $\hat{0}$ and $P$. alba $q \mathrm{x}$ P. euphratica ô.

\begin{tabular}{|c|c|c|c|c|c|c|c|c|c|c|c|}
\hline Groups of crosses & $\mathrm{I}^{3} \mathrm{H}^{* * *}$ & $\mathrm{CIJ}$ & $\mathrm{BN}$ & $\mathrm{BL}$ & $\mathrm{BA}$ & LL & $L W$ & LA & $\mathrm{SN}$ & $\mathrm{SL}$ & $\mathrm{SW}$ \\
\hline P euphatica ${ }_{\mathrm{T}} \times P$ alhat & $252 a$ & $26.6 a$ & $12.6 a$ & $87 b$ & $50.6 b$ & $10.0 \mathrm{a}$ & $3.7 \mathrm{~b}$ & $7.0 \mathrm{~b}$ & $123.0 \mathrm{a}$ & $32.0 \mathrm{a}$ & $25.0 \mathrm{a}$ \\
\hline P. alba $\mathrm{O}$ P euphaticad & $239 \mathrm{a}$ & $26.0 \mathrm{a}$ & $9.7 \mathrm{~b}$ & $112 \mathrm{a}$ & $61.9 \mathrm{a}$ & $7.4 \mathrm{~b}$ & $7.8 \mathrm{a}$ & $11.4 \mathrm{a}$ & $4.7 \mathrm{~b}$ & $22.1 \mathrm{~b}$ & $18.1 \mathrm{~b}$ \\
\hline
\end{tabular}

***: Abbreviations and scales of the measurements are described in Table 2.

Different letters indicate significant differences between hybrid groups, based on the studied characters. 


\section{Results}

Three hundred and seven inter-specific seedlings of the two groups of mating were produced and studied by a nested model based on a randomized complete block design. Significant variations were found in the studied characteristics at different levels of the studied genetic materials. The two groups of crosses were significantly different for majority of the studied characteristics. The hybrids nested in the groups were also significantly different for several characters such as branch number, plant diameter, leaf length and stomata characteristics (Table 3). Progenies nested in hybrids and groups were also significantly different for plant dimension characteristics, plant height and collar diameter as well as branch angle and leaf length.

Means of the two hybrid groups were classified into two separate groups based on majority of the studied characters (Table 4). Noticeable differences between the two hybrid groups were observed on stomata numbers, which varied from 4.7 to 123 between the two groups. Based on the leaf characteristics, the first group of crosses, with $P$. euphratica as their female parents, had longer leaves but less wide in width and smaller leaf area than the second group with $P$. alba as their female parents. In other words, average of leaf width for the first group of the crosses was $3.7 \mathrm{~cm}$, whereas, it was 7.8 $\mathrm{cm}$ for the second group. Branchiness pattern was also different between the two hybrid groups. The first group had more but shorter branches with less branch angle than the second group (Table 4). In addition to the mentioned characteristics, several other characters such as leaf overall appearance of the hybrids of the two groups were also highly different which is not recorded and analyzed due to qualitative nature of the characters.

Means of the six inter-specific hybrids within groups were also classified in several distinct groups for majority of the studied characters (Table 5). In other words, for some characteristics such as branch length, the first group of inter-specific hybrids varied between 84.8 to $88.4 \mathrm{~cm}$, whereas, the second group varied between 106.4 to $121.1 \mathrm{~cm}$. Leaf characteristics also showed significant different patterns. Leaf

Table 5. - Classification of poplar inter-specific hybrids, based on several morphologic and micro-morphologic characteristics.

\begin{tabular}{llllllllllll}
\hline Crosses & PII $^{\star \star x}$ & CD & BN & BL & BA & LL & LW & LA & SN & SL & SW \\
\hline PcPal & $260.0 \mathrm{a}$ & $29.1 \mathrm{a}$ & $12.7 \mathrm{a}$ & $88.4 \mathrm{c}$ & $54.3 \mathrm{~b}$ & $10.3 \mathrm{a}$ & $4.2 \mathrm{~b}$ & $8.2 \mathrm{c}$ & $130.2 \mathrm{a}$ & $29.7 \mathrm{a}$ & $23.9 \mathrm{a}$ \\
PePa2 & $240.9 \mathrm{a}$ & $23.2 \mathrm{c}$ & $12.5 \mathrm{ab}$ & $84.8 \mathrm{c}$ & $45.6 \mathrm{c}$ & $9.5 \mathrm{~b}$ & $3.0 \mathrm{~b}$ & $5.4 \mathrm{~d}$ & $112.9 \mathrm{~b}$ & $32.8 \mathrm{a}$ & $26.6 \mathrm{a}$ \\
PaPel & $239.7 \mathrm{a}$ & $27.5 \mathrm{a}$ & $10.1 \mathrm{~b}$ & $114.0 \mathrm{~b}$ & $62.0 \mathrm{a}$ & $6.9 \mathrm{~d}$ & $7.4 \mathrm{a}$ & $11.3 \mathrm{ab}$ & $4.8 \mathrm{c}$ & $20.4 \mathrm{c}$ & $16.4 \mathrm{c}$ \\
PaPc2 & $247.9 \mathrm{a}$ & $26.5 \mathrm{ab}$ & $9.4 \mathrm{~b}$ & $121.1 \mathrm{a}$ & $63.0 \mathrm{a}$ & $7.3 \mathrm{~d}$ & $7.9 \mathrm{a}$ & $10.0 \mathrm{bc}$ & $4.7 \mathrm{c}$ & $25.2 \mathrm{~b}$ & $20.8 \mathrm{ab}$ \\
PaPe3 & $231.2 \mathrm{a}$ & $26.3 \mathrm{ab}$ & $9.0 \mathrm{~b}$ & $106.6 \mathrm{~b}$ & $61.1 \mathrm{a}$ & $7.1 \mathrm{~d}$ & $7.5 \mathrm{a}$ & $10.7 \mathrm{ab}$ & $4.5 \mathrm{c}$ & $23.9 \mathrm{cb}$ & $20.1 \mathrm{~b}$ \\
PaPc4 & $236.4 \mathrm{a}$ & $24.3 \mathrm{bc}$ & $9.7 \mathrm{~b}$ & $106.4 \mathrm{~b}$ & $61.6 \mathrm{a}$ & $8.0 \mathrm{c}$ & $8.2 \mathrm{a}$ & $12.5 \mathrm{a}$ & $4.6 \mathrm{c}$ & $21.4 \mathrm{cb}$ & $17.7 \mathrm{bc}$ \\
\hline
\end{tabular}

***: Abbreviations and scales of the measurements are described in Tables 1 and 2.

Different letters indicate significant differences between inter-specific hybrids, based on the studied characters.

Table 6. - Phenotypic correlation coefficients between all pairs of the studied characteristics on poplar interspecific hybrids.

\begin{tabular}{|c|c|c|c|c|c|c|c|c|c|c|}
\hline Claracters & $\mathrm{PII}^{* * *}$ & (1) & $\mathrm{BN}$ & |3I. & BAA & 1.1 & LW & I.A & SN: & SI. \\
\hline Collar diameter & $0.50^{* *}$ & & & & & & & & & \\
\hline Branch number & $0.21^{* *}$ & $0.34^{* *}$ & & & & & & & & \\
\hline J3ranch Jength & $0.35^{4 *}$ & $0.45^{* *}$ & $0.05^{\mathrm{n}}$ & & & & & & & \\
\hline Branch angle & $0.07^{n 4}$ & $0.19^{* * *}$ & $0.05^{\mathrm{ni}}$ & $0.16^{* *}$ & & & & & & \\
\hline Leaf length & $0.26^{* *}$ & $0.19^{* *}$ & $0.13^{* *}$ & $0.11^{\mathrm{n}}$ & $-0.15^{* *}$ & & & & & \\
\hline Leaf width & $0.20^{* *}$ & $0.19^{* 4}$ & $-0.06^{\mathrm{ns}}$ & $0.33^{* *}$ & $0.23^{* *}$ & $0.31^{* *}$ & & & & \\
\hline I.eaf" area & $0.25^{* *}$ & $0.26^{* *}$ & $-0.03^{115}$ & $0.35^{* *}$ & $0.22^{* *}$ & $0.15^{x *}$ & $0.28^{* *}$ & & & \\
\hline Stomala number & $0.04^{1 \mathrm{~s}}$ & $0.04^{\mathrm{ns}}$ & $0.15^{* *}$ & $-0.27^{* \star}$ & $-0.33^{* *}$ & $0.37^{* *}$ & $-0.39^{* *}$ & $-0.25^{* *}$ & & \\
\hline Stomata length & $0.17^{* *}$ & $0.14^{*}$ & $0.23^{* *}$ & $0.01^{\mathrm{tlls}}$ & $-0.16^{* k}$ & $0.24^{* 4}$ & $-0.06^{\mathrm{T} s}$ & $0.10^{\text {1.1.5 }}$ & $0.2 l^{* *}$ & \\
\hline Stomata width & $0.14^{*}$ & $0.12^{*}$ & $0.2 !^{* *}$ & $0.02^{\text {n.t. }}$ & $-0.14^{*}$ & $0.21^{* *}$ & $-0.02^{195}$ & $0.09^{\text {ths }}$ & $0.16^{* *}$ & $0.96^{* *}$ \\
\hline
\end{tabular}

${ }^{* *}$ and ${ }^{*}=$ significant at $1 \%$ and $5 \%$ respectively, $\mathrm{ns}=$ not significant,

${ }^{* * *}:$ Abbreviations and scales of the measurements are described in Table 2. 
Table 7. - Mean squares, expected mean squares (EMS) and their percentage of total genetic originated variations of the studied characteristics.

\begin{tabular}{|c|c|c|c|c|c|c|c|c|c|c|c|}
\hline \multirow{2}{*}{$\begin{array}{l}\text { Characlers } \\
\text { Coriance componthents }\end{array}$} & \multicolumn{3}{|c|}{ Hybrid groups } & \multicolumn{3}{|c|}{ I lybrids within troups } & \multicolumn{3}{|c|}{ Ptomenjes within hybrids } & \multicolumn{2}{|c|}{ Lrror } \\
\hline & MS & E.:W & $4 / 6$ & $\mathrm{MS}$ & J.MS & $11 / 4$ & $M S$ & I:MS & $1 / \%$ & MS & $\%$ \\
\hline P'antheintal & 3578 & 8.8 & 0.22 & 1189 & -9.79 & 0.0 & 5271 & 662.5 & 16.5 & 3335 & 83.2 \\
\hline Collar diameter & 5.6 & -1.5 & 00 & 164 & 2.07 & 4.9 & 62 & 11,4 & 27.0 & 29 & 68.1 \\
\hline Branch number & 303 & 32.8 & 49.3 & $14 . \bar{j}$ & 5.12 & 7.7 & 33.5 & 1.75 & 2.6 & $23 . \overline{3}$ & 40.4 \\
\hline Branch licngli & 23126 & 297.1 & 27.2 & 1984 & 22.0 & 2.0 & 801 & 60.6 & 5.5 & $7] 4$ & 65.3 \\
\hline Branch ancrle & 6281 & 84.5 & 51.3 & 145 & 1.02 & 0.6 & 95 & 7.85 & 4.8 & 71 & 43.4 \\
\hline I.teaf length & 238 & 3.1 & 40.6 & 18 & 0.26 & 3.4 & 5.1 & 0.45 & 5.9 & 3.8 & 50.1 \\
\hline Lcaf widtlı & 638 & 8.6 & 51.7 & 11 & 0.04 & 0.2 & 9.1 & 0.59 & 3.5 & 7.4 & 44.6 \\
\hline Lcat'area & 730 & 9.3 & 28.8 & 65.4 & 0.67 & 2.1 & 32.7 & 5,36 & 16.6 & 17 & 52.5 \\
\hline Stomala tumber & 477884 & 6551 & 43.3 & 588 & 4.24 & 0.1 & 372 & $-32,0$ & 0.0 & 465 & 6.6 \\
\hline Slomala length & 2884 & 37.4 & 34.2 & 239 & 3.40 & 3.1 & 68 & -0.04 & 0.0 & 69 & 62.7 \\
\hline Slomala withl & 1742 & 22.1 & 25.6 & 199 & 2.83 & 3.3 & 58 & -1.29 & 0.0 & 61 & 71.1 \\
\hline
\end{tabular}

length varied between 9.5 to $10.3 \mathrm{~cm}$ within the first groups, whereas, it varied between 6.9 to 8 $\mathrm{cm}$ within the second group. Adaxial stomata number varied between 112.9 to 130.2 in the first group, which were classified in two different classes, whereas it varied between 4.5 to 4.8 within the second group. For other stomata characteristics also the inter-specific hybrids showed significant different patterns (Table 5).

Estimated correlation coefficients between all pairs of the studied characters are presented in Table 6. A great number of highly significant positive and negative correlation coefficients were observed between the studied characters (Table 6). Correlation patterns changed a lot within the hybrid groups, when correlation analysis was performed on the hybrid group's data set separately (data are not shown).

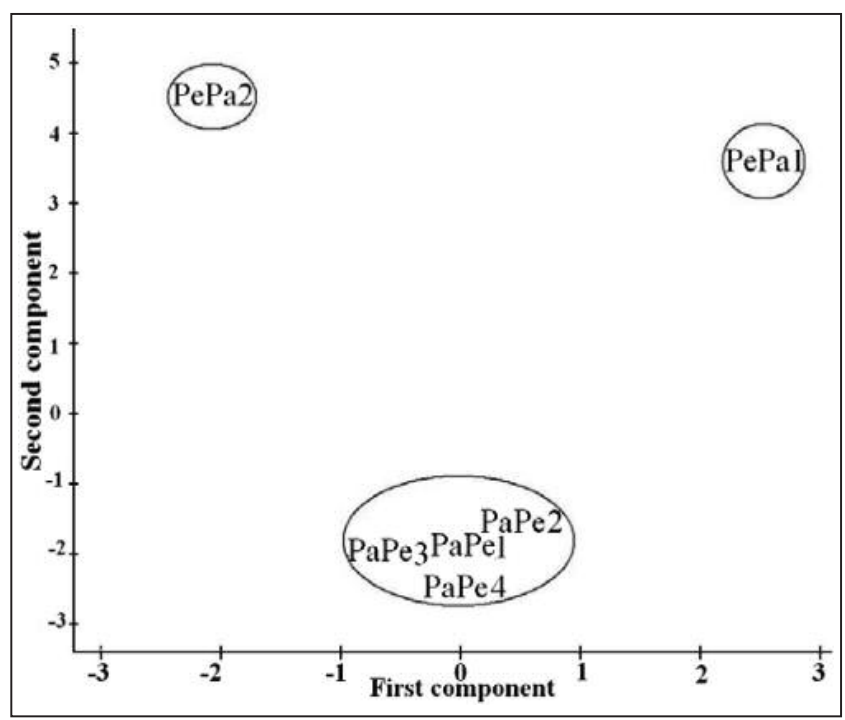

Figure 1. - Plot of the first two principal component scores, explaining more than $83 \%$ of existing variation within the mean values of six poplar inter-specific hybrids. Names inside the scatter-plot are described in Table 1.
Expected mean squares (EMS) and their percentage of total genetic originated variations of the studied characteristics are presented in Table 7. For several characteristics such as branch number, branch angle, leaf traits, and stomata number a great portion of variance components was observed on hybrid group level. Hybrids within group variance components were not strong, whereas, progenies within hybrids components were noticeable for plant height, plant diameter and leaf area. This portion of variance was negative for stomata characteristics. Majority of the variance components belonged to error portion of the components. In this regard it should be mentioned that a large portion of this source of variance component is genetic variation between the progenies within plots, which is not separated from the error values.

Principal components analysis on the studied characters mean values revealed an informative importance of the first two components by which $86 \%$ of existing variation between the mean values was justified in the first two eigenvalues. Except collar diameter, rest of the characters showed almost equal positive or negative effects on formation of the first component (data are not shown). Plotting the first two components separated the inter-specific hybrids into three distinct major classes (Figure 1). In other words, two hybrids of the first group located in two separate gropes whereas all of the four hybrids of the second group located in another distinct group.

\section{Discussion}

One of the major Populus breeding strategies is incorporation of inter-specific hybridization 
and vegetative propagation. By this strategy, genomes of distinct poplar species are combined to maximize and exploit genetic variation through clonal selection (STANTON et al., 2014). By present study, it was attempted to produce numerous hybrid plants between two Populus species, $P$. euphratica and $P$. alba to achieve several purposes. First to produce fast growing hybrids more productive than their parents, then to accumulate positive characteristics of the two species in their siblings and progeny families to broaden ecological zone of the species. Natural hybridization may occur in habitats of the two poplar species, but it is believed that many inter-specific hybrids of the species are characterized by low vitality and fertility. Furthermore, they are usually more poorly adapted to environmental conditions than their parental species. Poplar species mainly need specific environmental conditions, particularly at seedling stages of their life. Therefore, natural hybridization is not universal for poplar species. It may take place only in some particular habitats with suitable moisture and soil conditions. Otherwise, majority of naturally produced hybrids would be lost. Therefore, poplar hybridization must be performed artificially with intensive care on species adapted to harsh climatic conditions of most part of Iran. For the mentioned purposes, 307 full-sib progenies were produced by 6 different inter-specific crosses classified into two groups, morphologic and micro-morphologic, mainly growth characteristics were recorded on threeyear old hybrid trees to compare hybrid groups as well as hybrids within groups and progenies nested within hybrids.

Variation in branch characteristics was remarkable mainly at hybrid group level. In other words, the hybrid groups showed different morphology and structures. The first group had more but shorter and closer branches than the second hybrid group. In contrast the second hybrid group showed lower value of branchiness, higher values of branch length and branch angle. Since $P$. euphratica is normally heavily branched, it seems branchiness of the first hybrid group is mainly inherited by its female parent species. Clonal biomass characteristics such as lateral branch number, branch length and branch angle not only affect quantity and quality of final wood production but also they affect other important aspects such as nitrogen use efficiency (PARIS et al., 2015). Variation in nitrogen use efficiency was also found among clones of other important fast growing tree species such as willows (ADEGBIDI et al., 2001) and eucalypts (SAFOU-MATONDO et al., 2005).

The first hybrid group also had longer leaves but less wide and less leaf area than the second group. Based on results of other researches, leaf morphological characteristics are regarded as a basis for identification of poplar genotypes (Floate, 2004; Pearce et al., 2005). Leaf size and length/width ratio have shown wide genetic variation and a high degree of genetic control over juvenile leaf morphology (FARMER, 1996). In present study, high proportions of leaf characteristics variations were observed at hybrid groups level (40.6 to 51.7 percent, Table 7), which is implying the importance of inter-specific hybridization, when genetic variation broadening is concerned.

Stomatal characteristics such as number, size, and distribution between leaf surfaces vary widely among poplar species and even within a species vary by leaf adaxial or abaxial surfaces (PEARCE et al., 2005). The variation has shown evidences of adaptive acclimation and heritable variation (DunlaP and SteTtler, 2001). However, studies of temperate plant species or ecotypes in xeric conditions have indicated that smaller stomata and higher stomata number are associated with higher stomatal conductance (ABRAMS, 1994). Compared with most of other plant species, poplar species are characterized by high stomatal conductance (PEARCE et $a l ., 2005)$. In that case the first hybrid group in this study might have much higher stomatal conductance than the second group. Higher stomatal conductance might possibly enhance net photosynthesis in warm conditions (RODEN and Pearcy, 1993; Pearce et al., 2005). In this study attempt was partly made to characterize possible differences of leaf adaxial stomatal characteristics between sibling progenies of six different inter-specific poplar hybrids on which stomata was counted on adaxial leaf surface. Since abaxial stomata were not observed on the

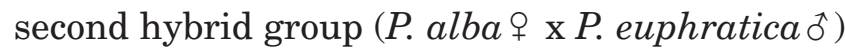
to be measured, adaxial stomatal characteristics of the two hybrid groups were recorded and compared. Our results revealed that stomata characteristics significantly varied both at hybrid groups and hybrids within groups levels. It should be mentioned that environmental conditions, leaf size, leaf age, and leaf microenvironment are effective factors on stomatal 
density of a mature leaf (YIN et al., 2004; LAKE et al., 2002). Huge differences observed between the two hybrid groups, with two different poplar species as female parent, would suggest substantial differences which deserve more attention. Average number of adaxial stomata varied between 4.7 to 123 for the two hybrid groups. Differences in the stomata number per unit area underlie differences in stomatal conductance which in its turn would cause differences in vegetative growth. Whereas, there were no such differences between vegetative characteristics of the two hybrid groups (Table 4). The second hybrid group had much less stomata on adaxial leaf surface (4.7), compared to the first group (123). In contrast the second hybrid group had a very condensed layer of white fuzz on abaxial leaf surface. McKown et al. (2014) recorded stomatal characteristics of $P$. trichocarpa, with amphistomatous leaves (stomata present on upper and lower leaf surfaces), by which mean adaxial stomatal density among their clones was 3.1 per $\mathrm{mm}^{2}$ and mean abaxial stomatal density was 183.9 per $\mathrm{mm}^{2}$. Their results on adaxial stomatal density $\left(3.1 / \mathrm{mm}^{2}\right)$ are similar to adaxial stomatal density of the second hybrid group of the present study $\left(4.7 / \mathrm{mm}^{2}\right)$. Average adaxial stomatal density of 7 clones of $P$. euphratica, collected from different habitats by CALAGARI et al. (2014), was recorded from 56.7 to 145.3 in natural habitats and from 68.3 to 113.8 in common field experimental conditions, which is close to the results of present study on the first hybrid group. YIN et al. (2004) suggested that environment has a large effect on stomatal characteristics. In other words, stomatal density has significant correlation with latitude of origin, as well as $\mathrm{CO}_{2}$ concentration. Even in one single plant stomatal development is influenced by mature leaves, where mature leaves detect environmental changes and relay the information to new developing leaves, causing an increase or decrease in number of stomata on new leaves (LAKE et al., 2002).

Since stomata are directly involved in respiration and photosynthesis (FILIPPOU et al., 2007; YADAV et al., 2011) fast growing trees must have much more stomatal density. Whereas, number of stomata on adaxial leaf surface of the second inter-specific hybrid group of the present study did not match with fast growing habit of the taxon which is almost the same as the first hybrid group. This may lead to suggest some kinds of photosynthesis and respiration func- tion such as leaf sub-stomatal chambers' functions for the mentioned fuzzy trichomes on abaxial leaf surface of the second hybrid group and their female parental species, $P$. alba, as well. This must be further studied in the future. Stomatal density has been one of the most common targets used to study water use efficiency (WUE) first in agricultural crops and then in hardwood tree species (NILSON and AssmanN, 2007; Vinocur and Altman, 2005). Less stomatal density may cause reduction in total water consumption (LOWSON et al., 2014). Stomatal density is also of key interest in the study of poplar clones for drought adaptation to semiarid conditions. Differences among plant species in stomatal characteristics may reflect adaptation to climatic differences (PEARCE et al., 2005). These differences between the poplar siblings of the present study with different genotypes may be used for selection and breeding of new poplar clones adopted to different climatic conditions. The superior genotypes also would be suitable to be assessed for suitability for bioenergy production in semi-temperate regions of the country as well as being suitable for timber production.

Highly positive significant correlation between plant height and collar diameter with leaf characteristics indicated that leaf length, leaf width and leaf area may be very informative and useful criteria for selecting high yielding poplar hybrids with indirect selection practices. Positive significant correlation between stomata dimensions also may provide useful tool for indirect selection for high yielding genotypes at young tree stage. Principal components analysis is a mathematical procedure which is used mainly for reducing dimensions of recorded data to be more interpretable. The scatter-plot, based on the first two principal components, classified the hybrids into 3 distinct groups, indicating the importance of the existing variation between the hybrid groups (Fig. 1).

Moreover, gene flow within the studied taxon may be accelerated by inter-specific hybridization. On the other hand, such kind of hybridization may lead to new speciation. Although we cannot yet predict whether a particular interspecific hybridization will be favorable to speciation or not. Anyhow, there are a great number of proponents of the importance of hybridization in evolution and speciation (Аввотт et al., 2013). 
Finally, an important fact to be taken into account in poplar breeding programs is selection of high yielding genotypes within natural or artificially produced poplar genetic variation. In present studies, by incorporation of genetic potentials of two major poplar species, a great number of new poplar genotypes were produced by which ecological zone of the commercially important species, $P$. alba, could be improved as well as new high yielding genotypes would be promising.

\section{Acknowledgments}

Research Institute of Forest and Rangelands of Iran supported this study for which we thank their sincere efforts and support. We also extend our sincere thanks to our colleagues at biotechnology group of the institute for all their assistances.

\section{References}

Aвbott, R., D. Albach, S. Ansell, J.W. Arntzen, N. BAIRD et al. (2013): Hybridization and speciation. Journal of Evolution and Biology 26: 229-246.

ABRAMS, M. D. (1994): Genotypic and phenotypic variation as stress adaptations in temperate tree species: a review of several case studies. Tree Physiology 14: 833-842.

Adegbidi, H. G., T. A. Volk, E. H. White, L. P. Abrahamson, R. D. BRigGS and D. H. Bickelhaupt (2001): Biomass and nutrient removal by willow clones in experimental bio-energy plantations in New York State. Biomass and Bioenergy 20: 399-411.

ARnold, M. and N. MARTin (2010): Hybrid fitness across time and habitats. Trends in Ecology and Evolution 25: 530-536.

Butlin, R. K. and M. G. Ritchie (2013): Pulling together or pulling apart: Hybridization in theory and practice. Journal of Evolutionary Biology 26: 294-298.

Calagari, M., A. Jalili, R. Abbas Azimi and P. SALEHI-Shanjani (2014): Environmental effects on leaf morphology traits in the Populus euphratica Oliv. Provenances of Iran. Iranian Journal of Forest and Poplar Research 22: 369-380, (In Persian).

Chauhan, N., M. S. Negi, V. Sabharwal, D. K. KhURANA and M. LAKSHMIKUMARAN (2004): Screening inter-specific hybrids of Populus (P. ciliate x maximowiczii) using markers. Theoretical and Applied Genetics 108: 951-957.

DunlaP, J. M. and R. F. STETTLER (2001): Variation in leaf epidermal and stomatal traits of Populus trichocarpa from two transects across the Wash- ington Cascades. Canadian Journal of Botany 79: 528-536.

FARMer, R. E. JR. (1996): The genecology of Populus. pp. 33-35. In: Biology of Populus and its Implications for Management and Conservation, edited by: R. F. Stettler, H.D. JR. Bradshaw, P.E. Hellman, and T. M. Hinckley, NRC Research Press, Ottawa.

Filippou, M., C. Fasseas and G. Karabourniotis (2007): Phootsynthetic characteristics of olive tree (Olea europaea) bark. Tree Physiology 27: 977-984.

FloAte, K. D. (2004): Extent and patterns of hybridization among the three species of Populus that constitute the riparian forest of southern Alberta, Canada. Canadian Journal of Botany 82: 253-264.

Jafari-Mofodabadi, A., A. R. Modirrahmati and A. TAVASSOLI (1998): Application of ovary and ovule culture in Populus alba L. x P. euphratica Olive. hybridization. Silvae Genetica 47: 332-334.

LAKE, J. A., F. I. WOODWARD and W. P. QUiCK (2002): Long-distance $\mathrm{CO}_{2}$ signaling in plants. Journal of Experimental Botany 53: 183-193.

LAWSON, S. S., P. M. PIJUT and C. H. MichleR (2014): The cloning and characterization of a poplar stomatal density gene. Genes and Genomics 36: 427-441.

Lopez, D. H., U. R. Sierra and M. D. Cristobal (2004): A comparison of isozyme and morphological markers to assess the within population variation in small populations of European aspen (Populus tremula L.) in Spain. Silvae Genetica 53(5-6): 227-233.

Marron, N., S.Y. Dillen and R. Ceulemans (2007): Evaluation of leaf traits for indirect selection of high yielding poplar hybrids. Environmental and Experimental Botany 61: 103-116.

McKown, A. D., R. D. Guy, L. Quamme, J. Klapste, J. L. Mantia, C. P. Constabel, Y. A. El-Kassaby, R. C. Hamelin, M. Zifkin and M. S. Azam (2014): Association genetics, geography and ecophysiology link stomatal patterning in Populus trichocarpa with carbon gain and disease resistance trade-offs. Molecular Ecology, doi: 10.1111/mec.12969.

Murashige, T. and F. Skooge (1962): A revised medium for rapid growth and bio-assays with tobacco tissue culture. Physiologia Plantarum 15: 473-597.

NiLSON, S. E. and S. M. Assmann (2007): The control of transpiration. Insights from Arabidopsis. Plant Physiology 143: 19-27

Paris, P., L. Mareschi, M. Sabatti, L. Tosi and G. SCARASCIA-Mugnozza (2015): Nitrogen removal and its determinants in hybrid Populus clones for bioenergy plantations after two biennial rotations in two temperate sites in northern Italy. iForest 8:668-676 [online 2015- 02-02] URL: http://www.sisef.it/iforest/contents/?id=ifor1254007.

Pearce, D. W., S. Millard, D. F. Bray and S. B. Rood (2005): Stomatal characteristics of riparian poplar species in a semi-arid environment. Tree Physiology 26: 211-218. 
Roden, J. S. and R.W. PEARCy (1993): The effect of flutter on the temperature of poplar leaves and its implications for carbon gain. Plant Cell Environment 16: 571-577.

Safou-Matondo, R., P. Deleporte, J. Laclau and J. Bouillet (2005): Hybrid and clonal variability of nutrient content and nutrient use efficiency in Eucalyptus stands in Congo. Forest Ecology and Management 210: 193-204.

Stanton, B. J., M. J. Serapiglia and L. B. Smart (2014): The Domestication and Conservation of Populus and Salix Genetic Resources. pp. 124-200. In: Poplars and Willows, Trees for Society and the Environment, edited by: IsEBrands, J. G. and J. Richardson, Published by FAO and CAB International, UK.

Tullus, A., L. RYTter, T. Tullus, M. Weih and H. Tullus (2012): Short-rotation forestry with hybrid aspen (Populus tremula L. $\times$ P. tremuloides Michx.) in Northern Europe. Scandinavian Journal of Forest Research 27: 10-29.
Tullus, A., H. Tullus, T. SoO and L. PÄRN (2009): Above-ground biomass characteristics of young hybrid aspen (Populus tremula L. $\times$ P. tremuloides Michx.) plantations on former agricultural land in Estonia. Biomass and Bioenergy 33: $1617-1625$.

Vinocur, A. and A. Altman (2005): Recent advances in engineering plant tolerance to abiotic stress: achievements and limitations. Current Opinion on Biotechnology 16: 123-132.

YAdAV, S. S., R. J. RedDEN, J. L. HATField, H. LotzeCAMPen, A. E. Hall and M. YADAV (2011): Crop Adaptation to Climate Change. Wiley-Blackwell, UK.

Yin, C.Y., B. L. DuAn, X. Wang and C.Y. Li (2004): Morphological and physiological responses of two contrasting Poplar species to drought stress and exogenous abscisic acid application. Plant Science 167: 1091-1097.

\title{
Mating system variation among populations, individuals and within and among fruits in Bertholletia excelsa
}

\author{
By L.H. O. WAdT ${ }^{1)}$, A. B. Baldoni ${ }^{2)}$, V.S. Silva ${ }^{3)}$, T. CAmpos $^{4)}$, K. Martins' ${ }^{5)}$, V.C. R. Azevedo ${ }^{6)}$, \\ L. R. MATA ${ }^{6)}$, A. A. Botin ${ }^{7)}$, E. S. S. Hoogerheide ${ }^{2)}$, H. Tonini ${ }^{2)}$ and A. M. SEBbenN ${ }^{8, *}$ )
}

(Received $5^{\text {th }}$ November 2015)

\begin{abstract}
The aim of this study was to investigate variation in mating system among three Brazilian Amazon populations of the tree Bertholletia excelsa with different levels of anthropogenic

\footnotetext{
1) Empresa Brasileira de Pesquisa Agropecuária (Embrapa), Embrapa Rondônia, BR $364 \mathrm{Km}$ 5,5. CEP 76.815-800, Porto Velho, RO, Brazil.

2) Empresa Brasileira de Pesquisa Agropecuária (Embrapa), Embrapa Agrossilvipastoril, Rodovia dos Pioneiros MT-222, Km 2,5. CEP 78550-970, Sinop, MT, Brazil.

3) Universidade Federal do Acre, Mestranda do Programa Ciência, Inovação e Tecnologia para a Amazônia, BR-364 Km 04, CP 500. CEP 69920-900, Rio Branco, AC, Brazil.

4) Empresa Brasileira de Pesquisa Agropecuária (Embrapa), Embrapa Acre, BR 364 Km 14. CEP 69908970, Rio Branco, AC, Brazil.

5) Universidade Federal de São Carlos, CCHB/Campus Sorocaba, Departamento de Biologia, Rodovia João Leme dos Santos (SP-264), Km 110. CEP 18052-780, Sorocaba, SP, Brazil.
}

interventions. We collected open-pollinated seeds from one natural population, remnant trees dispersed in a pasture, and trees from a plantation. Outcrossing rate not varied among the populations and indicates that all seeds were originated from outcrossing $\left(t_{m}=1.0\right)$. Mating among relatives was significant higher in the plantation than forest and pasture populations, probably due the fact that many trees are related in the plantation. Correlated mating was significantly higher in pasture $\left(r_{p}=0.47\right)$ and plantation $\left(r_{p}=0.51\right)$ than in the natural

\footnotetext{
6) Empresa Brasileira de Pesquisa Agropecuária (Embrapa), Cenargen, Parque Estação Biológica, PqEB, Av. W5 Norte (final). CEP 70770-917, Brasília, DF, Brazil.

$\left.{ }^{7}\right)$ Universidade Federal de Mato Grosso (UFMT), CEP 78550-000, Sinop, MT, Brazil.

8) Instituto Florestal de São Paulo, Estação Experimental de Tupi, Rodovia Luiz de Queiroz, km 149,5, CP 339, CEP 13400-970, Piracicaba, SP, Brazil.

*) Corresponding author: AlEXANDRE SEBBENN. E-Mail: alexandresebbenn@yahoo.com.br
} 